\title{
Ampelographic and Ampelometric Characterization of Berries and Seeds from Traditional Vineyards in Morocco ${ }^{+}$
}

\author{
Younes Hmimsa ${ }^{1,2, * \mathbb{D}}$, Widad Benziane ${ }^{2}$, Zineb Mouden ${ }^{2}$, Mohammed Ater ${ }^{2} \mathbb{D}$ and Salama El Fatehi ${ }^{1,2}$ \\ 1 Department of Life Sciences, Polydisciplinary Faculty, Abdelmalek Essaadi University, Larache 93004, \\ Morocco; elfatehisalama@gmail.com \\ 2 Bio-Agrodiversity Team, Laboratory of Applied Botany, Department of Biology, Faculty of Science, \\ Abdelmalek Essaâdi University, Tetouan 93030, Morocco; widaadbenziane@gmail.com (W.B.); \\ moudni.zineb@gmail.com (Z.M.); mohammed.ater@gmail.com (M.A.) \\ * Correspondence: y.hmimsa@uae.ac.ma; Tel.: +212-661-604-090 \\ + Presented at the 1st International Electronic Conference on Biological Diversity, Ecology and Evolution, \\ 15-31 March 2021; Available online: https:/ / bdee2021.sciforum.net/.
}

Citation: Hmimsa, Y.; Benziane, W.; Mouden, Z.; Ater, M.; El Fatehi, S. Ampelographic and Ampelometric Characterization of Berries and Seeds from Traditional Vineyards in

Morocco. Biol. Life Sci. Forum 2021, 2, 7. https://doi.org/10.3390/ BDEE2021-09523

Academic Editor: Luca Legal

Published: 22 March 2021

Publisher's Note: MDPI stays neutral with regard to jurisdictional claims in published maps and institutional affiliations.

Copyright: (c) 2021 by the authors. Licensee MDPI, Basel, Switzerland. This article is an open access article distributed under the terms and conditions of the Creative Commons Attribution (CC BY) license (https:// creativecommons.org/licenses/by/ $4.0 /)$.

\begin{abstract}
Morocco, like other Mediterranean countries, is characterized by a great diversity of indigenous varieties of vines, "Vitis vinifera ssp. vinifera", due to the climate and the heterogeneity of the landscapes, as well as the know-how and agricultural practices adopted by traditional farmers who have contributed preserving the genetic diversity of these indigenous grape varieties. Within the framework of this study, we seek the identification and characterization of 36 indigenous grape varieties sampled in northern and southern Morocco. The samples studied were taken from traditional vineyards in these regions. For the ampelographic and ampelometric descriptions, 26 characters were used according to a list of descriptors developed by the International Organization of Vine and Wine (OIV). Thus, the ampelographic and ampelometric approaches were refined by a principal component analysis (PCA), which made it possible to group the grape varieties into five distinct groups according to their correlations to the variables linked to the bunch, the berry, and the seed. The results obtained from these different approaches confirmed the presence of great inter-grape and intra-grape variability within the samples studied. This observation encourages us to make more efforts to maintain this variability and to fight against genetic erosion and the threat of environmental changes.
\end{abstract}

Keywords: vine; Vitis vinifera ssp. vinifera; traditional grape; ampelographic; ampelometric; OIV

\section{Introduction}

The history of vine cultivation is parallel to the history of civilization in the Mediterranean Basin. The oldest perennial and emblematic Mediterranean crops (the olive tree (Olea europaea L.), date palm (Phoenix dactylifera L.), and the fig tree (Ficus carica L.)) and the domestication of the vine (Vitis vinifera L.) dates back at least 6000 years [1-3]. Indeed, the first productions of grapes and wine were a source of income and added economic value [4]. In Morocco, like other countries in the Mediterranean Basin, the winemaking tradition dates back to ancient times. To the probable contributions of the Phoenicians and the Romans, the Arab imprint has been added, which, since the Middle Ages, has characterized the winemaking landscapes of the country $[5,6]$. Subsequently, the historical exchanges between the two Mediterranean shores, French colonialism, and the important diversity of the terroir have for centuries led to the development and evolution of a large number of grape varieties, especially for the production and export of wine [7-9]. Thus, Morocco is characterized by a great diversity of traditional grape varieties thanks to its climate and the heterogeneity of its landscape, but above all, thanks to the local knowledge and the agricultural practices of traditional farmers who have contributed to preserving the genetic diversity of these grape varieties [10-12]. However, in recent decades, the modernization of agriculture and the transformation of agricultural systems have placed genetic resources 
of plant origin in a worrying situation. In fact, modern vineyards made from European vines were gaining more space, to the detriment of traditional grape varieties, which have declined or even disappeared from the usual cultivation areas. From this perspective, given that valuation is a first step towards conservation, the present study focuses on the characterization of 36 traditional grape varieties via ampelometric and ampelographic parameters.

\section{Materials and Methods}

\subsection{Prospecting and Sampling}

The surveys were carried out at the scale of areas recognized by the persistence of traditional vineyards, using indigenous grape varieties. In this sense, at the scale of Morocco, the study was conducted at 14 sites belonging to two main zones: the Western Rif in the north and the High Atlas in the south (Figure 1). For this, the sampling was carried out in traditional vineyards, at the time of fruiting. From each site, with the help of the farmers, we collected samples of named and recognized fruits for each grape variety. In total, we sampled 27 grape varieties in the Western Rif and 9 grape varieties in the High Atlas (Table 1).

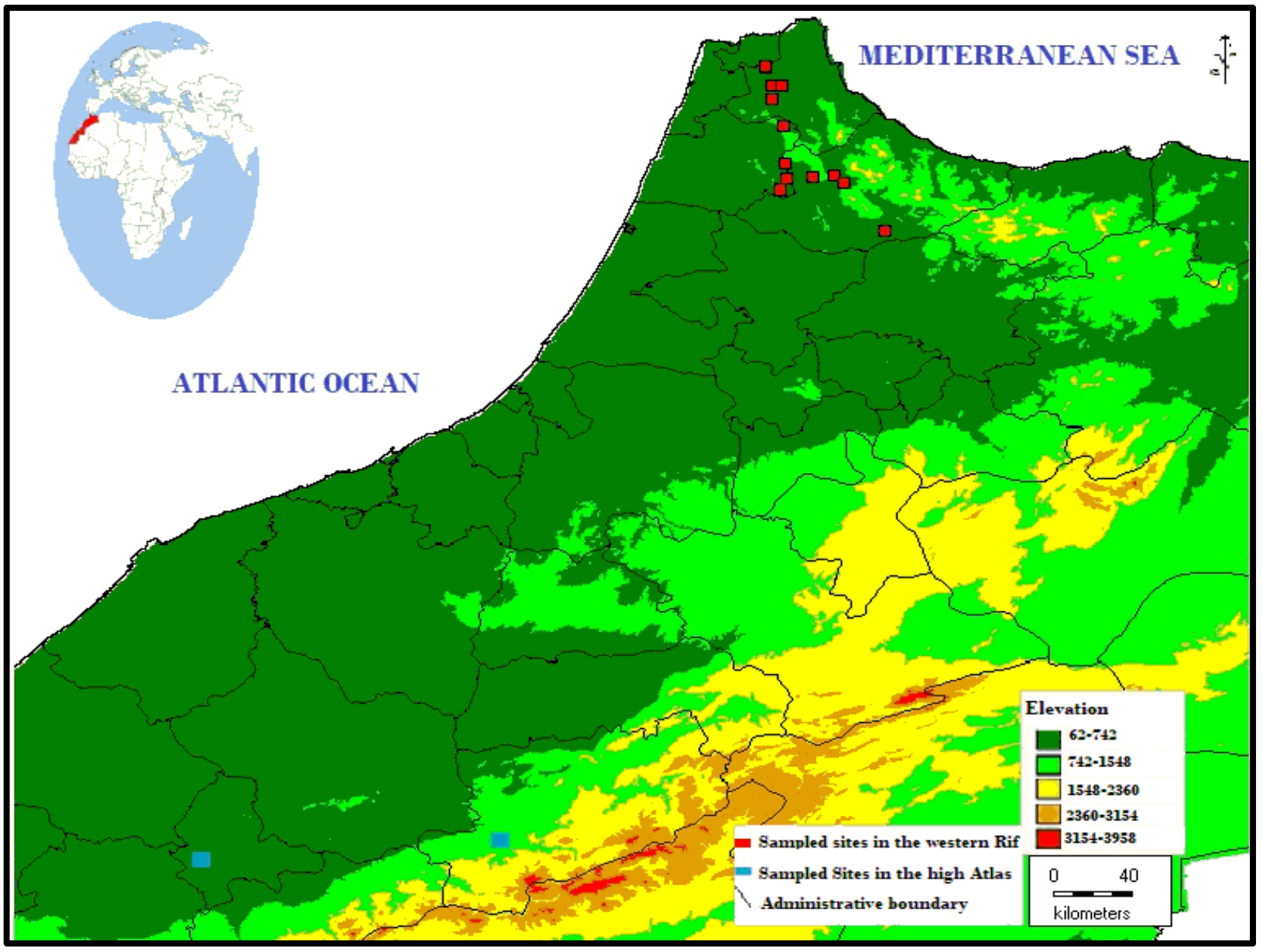

Figure 1. Location of the sampled sites across Morocco. 
Table 1. List of grape varieties sampled in different sites.

\begin{tabular}{cl}
\hline Region & \multicolumn{1}{c}{ Grape Variety (Code) } \\
\hline & Ainab lebyed (ALB), Ainab leKhal (ALk), Albaydi (ALBY), Elfassi (ALF), Alkouz (ALKO), Babbour Hmara \\
& (BABH), Bezzoul Alaouda (BZA), Bezzoul Alaouda Byed (BZAB), Bezoul Alaouda Hmar (BZAH), Boukhanzir \\
Western Rif & (BKH), Boukwaness (BKW), Chwikhi (CHW), Douak (DOU), Eddibani (EDD), Feqqass (FQS), Hmar Bouamar \\
& (HBA), Houmrani (HOU), Jenyani (JYN), Lechehab (LCH), Maticha (MTC), Sbyae Lebnat (SBLB), Taferyalet \\
& (TFR), Taferyalt Byed (TFRB), Taferyalet Lechehab (TFRL), Taferyalet sfar (TFRS), Taferyalet lekhal (TFRK), \\
& Valencia (VAL) \\
\hline \multirow{2}{*}{ High Atlas } & Abouhou (ABH), Bouchouka (BCHK), Guiyyar (GYR), Laadari (LAD), Tiglay n'Timilli (TGHL), Tiniwine (TNW), \\
& Aabbou (AAB), Feryali (FRY), Laadari Haouz (LADH) \\
\hline
\end{tabular}

\subsection{Ampelographic and Ampelometric Parameters}

According to the universal characteristics established by the OIV, the ampelographic and ampelometric descriptions of 36 indigenous Moroccan grape varieties were based on the use of 10 bunches of grapes/grape variety, 30 berries/each bunch of grapes, and 100 seeds [13]. In this context, the study was carried out according to 26 ampelographic and ampelometric characteristics selected from the list of descriptors developed by the International Organization of Vine and Wine (OIV) [13]. Thus, for the description of the grape clusters, 8 OIV descriptors were adopted: 202, 203, 204, 206, 207, 208, 209, and 502. For the description of the berries, 15 OIV descriptors were used: 220, 221, 222, 223, 225, 226, $229,231,232,235,236,238,240,503$, and 505 . For the characterization of the seeds, we used 4 OIV descriptors: 241, 242, 243, and 244.

\subsection{Statistical Analysis}

Using the XLSTAT software, we performed an analysis of variance and correlation.

\section{Results}

3.1. Ampelographic Parameters

3.1.1. Bunches of Grapes

The ampelographic notations carried out on the bunches of grapes from the different grape varieties showed a fairly high level of variability. From the point of view of the length of the bunches of grapes (OIV 202), we observed that the bunches of the different grape varieties have a length varying from short to very long. Thus, the clusters of the grape varieties $\mathrm{AAB}, \mathrm{BCHK}$, and TFRS are very long, while the bunches of the grape varieties $\mathrm{BABH}, \mathrm{BZAH}$, and SBLB are short.

Concerning the width of the bunches of grapes (OIV 203), ampelographic analysis revealed a great diversity in width between the different grape varieties. Thus, the widest bunches of grapes belong to the BCHK and LAAH grape varieties, and the very narrow to narrow bunches of grapes belong to the ALK grape variety. The grape clusters of 12 varieties show a narrow to medium width. From the point of view of the compactness of the bunches of grapes (OIV 204), the bunches of grapes of the different grape varieties have a very heterogeneous compactness, ranging from very loose to very compact. Thus, the grape varieties $\mathrm{BABH}, \mathrm{BKW}$, and MTC have very compact bunches of grapes, and the grape varieties $\mathrm{BZAB}, \mathrm{BKH}, \mathrm{EDD}$, and $\mathrm{LCH}$ have loose to very loose bunches of grapes. According to the character of the lignification of the peduncle (OIV 207), we note the presence of three categories; one presents the grape varieties with lignification, which are limited to the base only and are the most dominant (19 varieties), and the other are varieties are characterized by lignification at the half of the peduncle (ABH, ALK, BCK, FQS, TFRS, and TNW), and for the third category, the lignification extends beyond half of the peduncle (11 grape varieties).

From the point of view of the shape of the bunches of grapes (OIV 208), and taking into account the shapes proposed in the list of descriptors, we found the existence of three shapes (cylindrical, conical, and funnel-shaped) in the grape varieties studied with the 
predominance of the cylindrical shape, and the conical shape being the least common. Regarding the number of wings of the main bunch of grapes (OIV 209), our study revealed that more than half of the grape varieties have one to two wings while 14 grape varieties have no wings. However, in three grape varieties (EDD, TFR, and BCK), the presence of three to four wings was noted.

\subsubsection{Berries}

Based on our ampelographic analysis of the different grape varieties, we noticed that there is great heterogeneity. Bay length (OIV 220) varies from short to long. Thus, the seeds of most grape varieties are of medium length. Regarding the width of the berry (OIV 221), we have demonstrated a quasi-balanced distribution between two categories (narrow and medium), with a predominance of the first. For the size of the berry (OIV 222), our study confirmed the non-uniformity of the majority of the grape varieties studied (31), as only five grape varieties (ABH, BCK, JYN, ALF, GYR) were listed as having uniform berries. Thus, the ampelographic analysis of the shape of the berry (OIV 223) allowed us to confirm the dominance of the short elliptical shape, followed by the spherical shape.

The presence of the troncovoidal form was also demonstrated in three grape varieties (BZAH, HBA, and SBLB) and flattened spherical was seen in three grape varieties (BKW, MTC and TFRS). The long elliptical shape was revealed in a single grape variety (BCK). The grape varieties studied are distributed according to the color of their berries (OIV 225) into five clearly distinguished groups, each group of which is characterized by a clearly defined skin color: yellow green (17 grape varieties), blue-black (9 grape varieties), pink (5 grape varieties), red (3 grape varieties), and dark red-violet (2 grape varieties).

Regarding the uniformity of the color of the epidermis of berries in different grape varieties (OIV 226), we found that in 30 grape varieties, the color is uniform, and the color of the epidermis was not uniform in only six grape varieties (BABH, EDD, ALF, FRY, HBA, TFR). Concerning the umbilicus (OIV 229), we noted that it is hardly apparent in 25 grape varieties, while it is apparent in 11 grape varieties (BKW, DOU, ALK, EDD, FQS, TFRK, FRY, GYR, LADH, TGHL, TNW). Concerning the intensity of the anthocyanin coloration of the pulp (OIV 231), we found that it is varied depending on the grape variety. Thus, it is zero in three grape varieties (ALK, CHW and $\mathrm{LCH}$ ) and medium to very strong in most grape varieties. In terms of the succulence of the pulp (OIV 232), it is moderately juicy in most grape varieties (25) and not very juicy in only one grape variety $(\mathrm{ABH})$. For the character and firmness of the pulp (OIV 235), it was noted that all the berries of the grape varieties studied are slightly firm, with the exception of the berries of a single grape variety that is very firm, TGHL.

From the standpoint of ease of separation of the pedicel (OIV 240), we found that the pedicels of all the grape varieties are difficult to separate, and that it is easy only in three grape varieties (AAB, GYR, LADH). Regarding the weight of the berries, we noticed that most grape varieties have berries with a weight that varies from very low to low, while the berries with an average weight to grow are part of only six grape varieties $(\mathrm{ABH}, \mathrm{BCHK}$, GYR, ALB, BZA, and BZAB). For the sugar content of the must (OIV 505), we noticed that 22 grape varieties have a high content, 11 grape varieties have an average content, and very high content was noted in 3 grape varieties (VAL, ALK, TNW).

\subsubsection{Seeds}

According to the analysis of the ampelographic characters related to the seeds of the different grape varieties, we observed that there are characters that do not discriminate between the different grape varieties, including the formation of seeds (OIV 241), which was found to be complete in all the grape varieties, as well as the transverse groove on the gold-dirty side of the seeds (OIV 244), which is also absent in all of the seeds.

Thus, the difference between the seeds of the various grape varieties was noted in relation to the level of the length of the seeds (OIV 242), which varies from medium to long with a predominance of the average length of the seeds. In addition, the seed weight (OIV 
243) shows a variation between the different grape varieties. It varies from low to very high. The weight is medium to very high in most of the seeds, and it is only low in two grape varieties (ALK and ALK).

\subsection{Ampelometric Parameters}

\subsubsection{Analysis of Variance}

The analysis of variance for the different ampelometric characteristics measured shows a highly significant difference between the different grape varieties studied $(p<0.001)$, which is the result of significant intra and inter grape variety. This difference is more expressed with very high Fs, particularly for the characteristics relating to the weight of the bunch and the seed (Table 2).

Table 2. Results of the analysis of variance of ampelometric characteristics.

\begin{tabular}{ccccccccccc}
\hline OIV & $\mathbf{2 0 2}$ & $\mathbf{2 0 3}$ & $\mathbf{2 0 6}$ & $\mathbf{5 0 2}$ & $\mathbf{2 2 0}$ & $\mathbf{2 2 1}$ & $\mathbf{2 3 8}$ & $\mathbf{5 0 3}$ & $\mathbf{2 4 2}$ & $\mathbf{2 4 3}$ \\
\hline Fisher's F & 3104 & 3104 & 3428 & 7114 & 5695 & 2646 & 5406 & 4083 & 6760 & 8320 \\
\hline $\operatorname{Pr}>$ F & $<0.0001$ & $<0.0001$ & $<0.0001$ & $<0.0001$ & $<0.0001$ & $<0.0001$ & $<0.0001$ & $<0.0001$ & $<0.0001$ & $<0.0001$ \\
\hline
\end{tabular}

The highest grape bunch length (OIV 202) was observed in the LADH grape variety $(326 \mathrm{~cm})$ while the lowest average was observed in the BABH grape variety $(130 \mathrm{~cm})$. Regarding the bunch width, we noticed that the greatest width was observed in LADH $(214 \mathrm{~cm})$, while the lowest is that of the ALK grape variety $(86.25 \mathrm{~cm})$. For the length of the peduncle, we found that it varies between $100 \mathrm{~cm}$ in the JYN grape variety and $30 \mathrm{~cm}$ in SBLB. In addition, the bunch weight showed a strong differentiation in variance, which is much higher than the other parameters measured. In fact, it varies between $1186.5 \mathrm{~g}$ in LADH and $112.65 \mathrm{~g}$ in FER.

Regarding the berries, we revealed that the berry length varies between $27.75 \mathrm{~mm}$ at BCHK and $15 \mathrm{~mm}$ at HOU, for which we also noted the smallest berry width $(14 \mathrm{~mm})$, while BZA is characterized by the widest width with an average of $21.25 \mathrm{~mm}$. In addition, analyzes of variance revealed that the TFR grape variety has the longest pedicel with an average value of $10.973 \mathrm{~mm}$, while the TFRS variety had the shortest pedicel with an average of $6.25 \mathrm{~mm}$. For the weight of the berry, we marked a strong differentiation; in fact, the highest weight is $6.36 \mathrm{~g}$, which was noted at BZA, while the ALKO grape exhibited the lowest weight with an average of $1.03 \mathrm{~g}$.

From a seed point of view, we found that the seeds have a more or less homogeneous length in most grape varieties, of which we noticed the highest length in LADH $(7.858 \mathrm{~mm})$, while the lowest length was noted in DOU $(5.65 \mathrm{~mm})$. Conversely to the length, the weight of the seeds showed a great variance between the different grape varieties; the highest weight was noted in $\mathrm{ABH}$ with an average of $79.74 \mathrm{mg}$, while ALKO had the lowest weight with an average of $30.01 \mathrm{mg}$.

\subsubsection{Correlation Matrix of Variables}

The analysis of the correlations between the measured parameters highlighted the presence of links between the various quantitative parameters (Table 3). Indeed, it appears that there is a positive and very significant correlation: firstly, between the parameters of the bunch of grapes, particularly the length of the cluster (OIV 202) with the width (OIV 203), and the weight of the bunch (OIV 502) with the length (OIV 202) and the width of the bunch (OIV 203); and secondly, between certain parameters of the berry, including the berry weight (OIV 503), which is strongly and positively correlated with the length (OIV 220) and the width of the berry (OIV 221). In addition, we found that there is a positive and highly significant correlation between the length (OIV 242) and the weight of the seeds (OIV 243). The length of the pedicel (OIV 238) and the sugar content of the must (OIV 505) did not show any correlation with any parameter. 
Table 3. Correlation matrix of the different variables analyzed.

\begin{tabular}{|c|c|c|c|c|c|c|c|c|c|c|c|}
\hline OIV & 202 & 203 & 206 & 502 & 220 & 221 & 238 & 503 & 242 & 243 & 505 \\
\hline 202 & 1 & 0.795 & 0.543 & 0.783 & 0.371 & 0.230 & 0.029 & 0.246 & 0.397 & 0.292 & -0.055 \\
\hline 203 & & 1 & 0.533 & 0.835 & 0.481 & 0.374 & 0.003 & 0.436 & 0.419 & 0.250 & -0.050 \\
\hline 206 & & & 1 & 0.284 & 0.272 & -0.042 & 0.078 & 0.265 & 0.260 & 0.221 & -0.194 \\
\hline 502 & & & & 1 & 0.472 & 0.464 & -0.138 & 0.447 & 0.503 & 0.371 & -0.100 \\
\hline 220 & & & & & 1 & 0.359 & -0.057 & 0.624 & 0.404 & 0.388 & -0.233 \\
\hline 221 & & & & & & 1 & 0.077 & 0.714 & 0.459 & 0.341 & 0.084 \\
\hline 238 & & & & & & & 1 & 0.055 & 0.097 & -0.049 & 0.258 \\
\hline 503 & & & & & & & & 1 & 0.574 & 0.579 & -0.238 \\
\hline 242 & & & & & & & & & 1 & 0.847 & -0.224 \\
\hline 243 & & & & & & & & & & 1 & -0.402 \\
\hline 505 & & & & & & & & & & & 1 \\
\hline
\end{tabular}

\section{Discussion}

Based on the ampelographic approach, the majority of the parameters used demonstrate the existence of fairly significant inter-varietal and intra-varietal variability. In addition, and on the ampelometric level, the statistical approach by the ANOVA test revealed the most discriminating parameters, showing a strong differentiation of variance for two characters: the weight of the bunch and seed.

According to the different ampelometric and ampelographic results obtained, we can confirm the presence of a clear differentiation, not only within the same grape variety, but also between the different grape varieties. This observation is justified by the example of grape varieties characterized by several features at the same time. The HBA variety is a perfect example of this variability, since its bunch is characterized by a short to medium length (202), narrow to medium width (203), loose to medium compactness (204), and a cylindrical and conical shape (208).

The comparison of the ampelographic and ampelometric characteristics of traditional Moroccan grape varieties with other Mediterranean grape varieties has confirmed the existence of a significant diversity but also a resemblance of some ampelographic characteristics, particularly the shape of the berry and the color of the epidermis. For the character of the shape of the berry, we note a dominance of the spherical and short elliptical shape among Moroccan grape varieties; the same results were obtained in varieties from Montenegro [14], Palestine [15], Slovenia [16], and Spain [17]. With regard to the color of the epidermis, it has been observed that almost all Moroccan grape varieties are yellow-green and blue-black in color, a finding which is in line with the results of the work carried out on grape varieties from Spain [17]. However, taking into account the fact that the morphological characteristics vary considerably depending on the region, ecology, care practices, and location, it can be said that these results should also be validated using molecular biology techniques.

\section{Conclusions}

This work constitutes an opportunity to better understand the Moroccan wine heritage and to compare Moroccan grape varieties to those of other Mediterranean countries. It is, therefore, a study to be completed by molecular characterization approaches. In fact, the importance of the characterization of a rare viticultural genetic resource can be explained through the identification of grape varieties that are tolerant to changing climatic conditions (e.g., drought, increased resistance to pathogenic agents) and could promote sustainable viticulture. 
Supplementary Materials: The poster presentation is available online at https:/ /www.mdpi.com/ article/10.3390/BDEE2021-09523/s1, the video presentation is available online at https:/ /sciforum.net/ event/BDEE2021/keynote/321fe49e58b7ee362e0f8201ead1dd6f/presentation_video/Hmimsa\%20et\% 20al.mp4

Acknowledgments: The authors thank the farmers of the various villages who contributed to the realization of this study. This research was funded by ARIMNET 2 Project "MedVItis", convention no. 7 .

Conflicts of Interest: The authors declare no conflict of interest.

\section{References}

1. Zohary, D.; Spiegel-Roy, P. Beginnings of fruit growing in the old world. Science 1975, 187, 319-332. [CrossRef] [PubMed]

2. Levadoux, L. Les populations sauvages et cultivées de Vitis vinifera L. Ann. Amél. Plantes 1956, 1, 59-118.

3. Olmo, H.P. The origin and domestication of the Vinifera grape. In The Origins and Ancient History of Wine, 1st ed.; McGovern, P.E., Fleming, S.J., Katz, S.H., Eds.; The Gordon and Breach Publishing Group: London, UK, 1996; pp. 31-43. [CrossRef]

4. McGovern, P.E.; Rudolph, H.M. The analytical and archaeological challenge of detecting ancient wine: Two case studies from the ancient near east. In The Origins and Ancient History of Wine, 1st ed.; McGovern, P., Fleming, S.J., Katz, S.H., Eds.; The Gordon and Breach Publishing Group: London, UK, 2000; pp. 57-67.

5. $\quad$ El Faïz, M. Faculté des sciences juridiques, économiques et sociales (Maroc). Étude thématique 'Les Paysages Culturels Viticoles' dans le cadre de la Convention du Patrimoine mondial de l'UNESCO; Les Vignobles De L'oudaya De Marrakech: Larache, Morocco, 2005; 133p.

6. Ater, M.; El Fatehi, S.; El Oualkadi, A.; Hmimsa, Y. La cultura tradicional de la vid en la región norte de Marruecos: Existencia de posibles influencias Andaluzas. In La vid en al-Andalus: Tradición, Diversidad y Patrimonio; Carabaza, M.J., Esteban HernanándezBermejo, S.J., Eds.; Comares Editorial: Granada, Spain, 2020; pp. 279-294.

7. Damade, P. La vigne et le Vin au Maroc. Thèse de Doctorat, Faculté de Droit-Université de Paris, Paris, France, 1936.

8. BVM (Bulletin Viticole du Maroc). La viticulture marocaine devant la Metropole. Journal BI-Mensuel D'Informations Professionnelles et de Défense des Intérêts de la Viticulture 1937, 2,12p.

9. Mahé, H. Préservation et Valorisation des Cépages Rares des Régions Nord-Méditerranéennes; Institut des Hautes Etudes de la Vigne et du Vin (IHEV): Montpellier SupAgro, France, 2015.

10. Hmimsa, Y.; Ater, M. Agrodiversity in the traditional agrosystems of the Rif mountains (North of Morocco). Biodivers. J. Life Earth 2008, 9, 78-81. [CrossRef]

11. Hmimsa, Y.; Ater, M. Le savoir-faire paysan: Quelques exemples. Regards sur les Patrimoines et les Terroirs des Jbala. In Proceedings of the Ministère de la Culture, 3éme Forum International Planète-Terroirs, Chefchaouen, Morocco, 31 May-2 June 2010; pp. 69-74.

12. El Oualkadi, A.; Ater, M.; Messaoudi, Z.; El Heit, K.; Laucou, V.; Boursiquot, J.M.; Lacombe, T. Genetic diversity of Moroccan grape accessions conserved ex situ compared to Maghreb and Europe gene pools. Tree Genet Genome 2011, 7, 1287-1298. [CrossRef]

13. OIV. Organisation Internationale de la Vigne et du Vin. In OIV Descriptor List for Grape Varieties and Vitis Species, 2nd ed.; Organization Intergouvernementale crée par l'Accord International: Paris, France, 2001.

14. Vesna, M. Ampelographic and Genetic Characterization of Montenegrin Grapevine Varieties. In Advances in Grape and Wine Biotechnology, 1st ed.; Morata, A., Loira, I., Eds.; Intech Open: Granada, Spain, 2019; pp. 55-67. [CrossRef]

15. Rezq, B. Ampelographic characterization of white grapevine cultivars (Vitis vinifera L.) grown in Palestine. PTUK 2015, 3, 1-11.

16. Hladnik, M.; Jakše, J.; Bandelj, D.; Vuk, I. The characterisation of Vitis vinifera 'Refošk' with AFLP and SSR molecular markers and ampelographic traits. Acta Agric. Slov. 2014, 103, 55-64. [CrossRef]

17. Gago, P.; Santiago, J.L.; Boso, S.; Villaverde, A.V.; Orriols, I.; Martínez, M. Identity of three grapevine varieties from a rediscovered viticulture region in northwest Spain. J. Int. Sci. Vigne. Vin. 2011, 45, 245-254. [CrossRef] 